\title{
The hurried consumer: Time-saving perceptions of Internet and catalogue shopping
}

Received: 22nd July, 2002

\section{Dr Pamela L. Alreck}

is a Professor of Marketing in the Franklin P. Perdue School of Business at Salisbury University, Salisbury, Maryland, USA She received her Doctorate from US International University and formerly taught at San Diego State University and Bentley College, Boston. She is an author of 'The survey research handbook', 'Why they buy: American consumers inside and out' and numerous academic articles.

\section{Dr Robert B. Settle}

is a Professor of Marketing in the Franklin P. Perdue School of Business at Salisbury University, Salisbury, Maryland, USA and Emeritus Professor of Marketing at San Diego State University. His doctorate is from the University of California, Los Angeles. $\mathrm{He}$ is an author of 'Why they buy: American consumers inside and out', 'The survey research handbook' and numerous academic articles.

\begin{abstract}
This study explored the relationship between consumer activity level and time stress and perceptions and practices regarding catalogue and online purchasing. There was a sharp contrast between perceptions and practices. Internet and catalogue shopping were perceived as time-savers; yet, respondents only rarely purchased from them to save time. Hours worked outside the home and time spent on the Internet were significantly related to Internet and catalogue time-saving perceptions and practices. Self-reported activity levels had little effect. Disparity between Internet time-saving perceptions and practices were attributed to difficulty of online shopping, implying that relationship management strategies grounded in enhanced databases might be promising.
\end{abstract}

Pamela L. Alreck Perdue School of Business, Salisbury University, Salisbury, MD 21801, USA.

Tel: + 1 410-548-5390; Fax: +1 410 546-6208; e-mail: plalreck@salisbury.edu

\section{INTRODUCTION}

Several contemporary economic and social forces create relatively high levels of time pressure on today's consumers. The prevalence of two-earner households, together with the demands of family and community life, leave many consumers with little time for leisurely shopping. As a result, it might be supposed that consumers would attempt to 'buy time', so to speak, by turning to shopping methods and outlets that reduce the amount of time they must spend on shopping.

\section{Background}

The effect of time pressure on human judgment, choice behaviour and decision making in general has been studied quite extensively and reported in the behavioural science literature. ${ }^{1-9}$ The effect of time pressure on consumer purchase decisions has also received attention by researchers, but to a far lesser degree. ${ }^{10-12}$ Typically in these studies the time pressure is induced as part of the experimental manipulation, rather than an enduring, situational fact of the subjects' everyday life. Nor do 
any of these studies focus on the relationship between time pressure and choice of shopping modes or purchase outlets.

Interactive or direct shopping modes - Internet and catalogue shopping are often cited as attractive because they are thought to save the buyer time. Bhatnagar et al. note that, 'In this increasingly time-constrained world, Internet stores allow consumers to shop from the convenience of remote locations. ${ }^{13}$ Similarly, Eastlick and Feinberg found that, 'Functional motives, including ... convenience were the strongest motives in influencing catalog shopping. ${ }^{14}$ Without the necessity to travel to and from a store location or to browse within one or more stores, interactive shopping allows the consumer to concentrate entirely on obtaining information and making a purchase decision. The value of this benefit, usually included under the rubric of convenience, could be expected to depend in part on the degree of time pressure experienced by the consumer, as well as the consumers' perceptions of the medium's time-saving potential.

Several researchers have attempted to identify the role of convenience as well as other predictors of online consumer purchasing, sometimes with somewhat surprising results. Bellman et al. found, 'The first of several surprises is that demographics alone do not seem to influence whether or not people buy online, nor the amount of money they spend there. It has more to do with whether they like being online and whether the time they have for buying things elsewhere is limited. ${ }^{15}$ Donthu and Garcia reported that, 'Internet shoppers are more convenience seekers ... than Internet non-shoppers are. ${ }^{16}$

Aside from the effects of convenience and demographic factors on consumer online shopping and buying, other variables that have been shown to be relevant include attitudes toward advertising and direct marketing, ${ }^{17}$ overall amount of Internet use and domain specific innovativeness, ${ }^{18}$ necessity or intention to search for information, ${ }^{19}$ financial security of transactions, ${ }^{20}$ accessibility and selection, ${ }^{21}$ brand name and price ${ }^{22,23}$ and, perhaps most important, the prospective customer's degree of risk acceptance or aversion. ${ }^{24,25}$

Together with the variables reported in these studies, the convenience of online shopping and buying was a significant factor in the majority of reports. Economy of both time and effort might be regarded as the main constituents of 'convenience'. Although 'time-saving' is not entirely synonymous with 'convenient', time is certainly an important factor, and perhaps the primary one in the minds of many people. It is to the role of time perception, availability and pressure that this study is directed.

\section{Research questions}

1 Do consumers perceive Internet and catalogue shopping and/or buying as more time saving or time consuming than other modes of shopping and/or buying?

2 How often do consumers use Internet and catalogue shopping as time-saving methods of shopping, compared to other time-saving practices?

3 To what degree do consumer activity levels affect their time-saving perceptions and use of time-saving shopping methods?

\section{METHODOLOGY}

A convenience sample of adult consumers from the general public in the Mid-Atlantic region of the USA was surveyed. Respondents completed a self-administered questionnaire delivered 
to and retrieved from them by university student field workers. Each field worker was assigned a quota of two men and two women from each age decade from the 20s to the 60s and over. The questionnaire was accompanied by a covering letter explaining the nature of the project and seeking the respondents' participation. The survey yielded a sample of 1,794 respondents.

\section{Activity levels}

Respondents reported their activity level in the first section of the questionnaire by completing the Activity scale of the F-A-S-T Time Orientation Test. ${ }^{26}$ This standardised scale contains 16 items in the form of statements to which respondents indicated their degree of agreement or disagreement on a five-point scale. The items, listed in Figure 2, were so inclined that agreement with half of them indicated high activity or time pressure and agreement with the other half meant low activity or time pressure. When processed, the possible range of scale scores was from 0 to 64 , with the higher scores representing greater activity or time pressure.

\section{Perceptions of time saving}

The second section of the questionnaire contained seven items listing shopping and/or buying modes for goods and services (eg 'Shopping and/or buying on the Internet or Web'). The seven items are listed in Figure 3. Respondents registered their perceptions of each on a five-point scale with extremes labelled 'time saving' and 'takes extra time'.

\section{Time-saving purchases}

In the third section of the questionnaire, respondents indicated how often they took each of 14 shopping or buying actions in order to save time, including 'Buy from the Internet or Web to save time' and 'Buy from catalogues to save time'. Other examples included 'Shop when stores aren't busy to save time' and 'Shop at the closest stores to save travel time'. The complete list of items is shown in Figure 4. They responded using a five-point verbal frequency scale with extremes labelled 'always' and 'never', with the midpoint labelled 'sometimes'.

\section{Computer and Internet use}

The fourth section of the questionnaire measured computer availability and Internet access at home and at work, as well as hours spent using the computer. The number and value of Internet, catalogue and television shopping channel purchases were also obtained in this section.

\section{Demographic data}

The demographic status of the respondent was obtained in the final section of the questionnaire. In addition to the respondents' occupational category and employment status, the number of hours they worked outside the home was also recorded.

\section{RESULTS}

The demographic distributions of the responding sample are shown in Table 1. Since field workers were assigned quotas of equal number of men and women in each age decade, these proportions are nearly equal, rather than representational of the underlying population. The responding sample proved to be somewhat higher in socioeconomic status than the general population as a whole. 
Table 1: Demographic status of the responding sample

\begin{tabular}{|c|c|c|c|c|c|}
\hline Variable & $\mathbf{N}$ & Percentage & Variable & $\mathbf{N}$ & Percentage \\
\hline Sex & & & Employment & & \\
\hline Male & 909 & 50.7 & Company employed & 804 & 44.8 \\
\hline Female & 885 & 49.3 & Employed in education & 205 & 11.4 \\
\hline \multirow[t]{2}{*}{ Total } & 1,794 & 100.0 & Government employed & 120 & 6.7 \\
\hline & & & Self-employed & 172 & 9.6 \\
\hline Age & & & Seeking employment & 10 & 0.6 \\
\hline Twenties & 386 & 21.5 & Student & 180 & 10.0 \\
\hline Thirties & 357 & 19.9 & Homemaker & 67 & 3.7 \\
\hline Forties & 356 & 19.8 & Retired & 236 & 13.2 \\
\hline Fifties & 353 & 19.7 & Total & 1,794 & 100.0 \\
\hline Sixties up & 342 & 19.1 & & & \\
\hline \multirow[t]{2}{*}{ Total } & 1,794 & 100.0 & Occupation & & \\
\hline & & & Professional & 153 & 8.5 \\
\hline Marital status & & & Executive, Manager & 118 & 6.6 \\
\hline Married & 1,048 & 58.4 & Engineering, Technical & 64 & 3.6 \\
\hline Not married & 746 & 41.6 & Administrative, Clerical & 97 & 5.4 \\
\hline \multirow{2}{*}{ Total } & 1,794 & 100.0 & Sales, Marketing & 76 & 4.2 \\
\hline & & & Skilled craft or trade & 114 & 6.4 \\
\hline Family size & & & Semi-skilled work & 48 & 2.7 \\
\hline Single & 319 & 17.8 & Student, Home, Retired & 1,124 & 62.7 \\
\hline Couple & 1,046 & 58.3 & Total & 1,794 & 100.0 \\
\hline Family & 429 & 23.9 & & & \\
\hline \multirow[t]{2}{*}{ Total } & 1,794 & 100.0 & Family Income & & \\
\hline & & & Under $20 \mathrm{k}$ & 142 & 7.9 \\
\hline Education & & & $20 \mathrm{k}$ to $39 \mathrm{k}$ & 256 & 14.3 \\
\hline Some high school & 72 & 4.0 & $40 \mathrm{k}$ to $59 \mathrm{k}$ & 239 & 13.3 \\
\hline High school graduate & 571 & 31.8 & $60 \mathrm{k}$ to $79 \mathrm{k}$ & 218 & 12.2 \\
\hline Some college & 467 & 26.0 & $80 \mathrm{k}$ to $99 \mathrm{k}$ & 135 & 7.5 \\
\hline College graduate & 404 & 22.5 & $100 \mathrm{k}$ to $119 \mathrm{k}$ & 114 & 6.4 \\
\hline Post-graduate & 280 & 15.6 & $120 \mathrm{k}$ and over & 159 & 8.9 \\
\hline \multirow[t]{2}{*}{ Total } & 1,794 & 100.0 & Refused & 531 & 29.6 \\
\hline & & & Total & 1,794 & 100.0 \\
\hline \multicolumn{6}{|l|}{ Work hours } \\
\hline None & 326 & 18.2 & & & \\
\hline Under 40 & 468 & 26.1 & & & \\
\hline 40 hours & 456 & 25.4 & & & \\
\hline Over 40 & 544 & 30.3 & & & \\
\hline Total & 1,794 & 100.0 & & & \\
\hline
\end{tabular}

\section{Computer and Internet use}

The percentage distributions of computer availability and Internet access at home and at work for the responding sample are shown in Figure 1. The results indicate a high level of access, with less than 13 per cent with no computer availability and only 19 per cent without Internet access at either location.

\section{Activity scale distributions}

The 16 items on the activity scale are shown in Figure 2, together with the percentage distributions of response for each item. The positive and negative items are listed according to the degree of agreement or disagreement with each, rather than in the sequence used on the questionnaire. The internal consistency reliability of the 16 items for the 1,794 respondents participating, measured by coefficient alpha, was .80. The mean and standard deviation for this sample did not differ significantly from those reported for the activity scale for the standardisation sample of the F-A-S-T Time Orientation Test. ${ }^{27}$ 


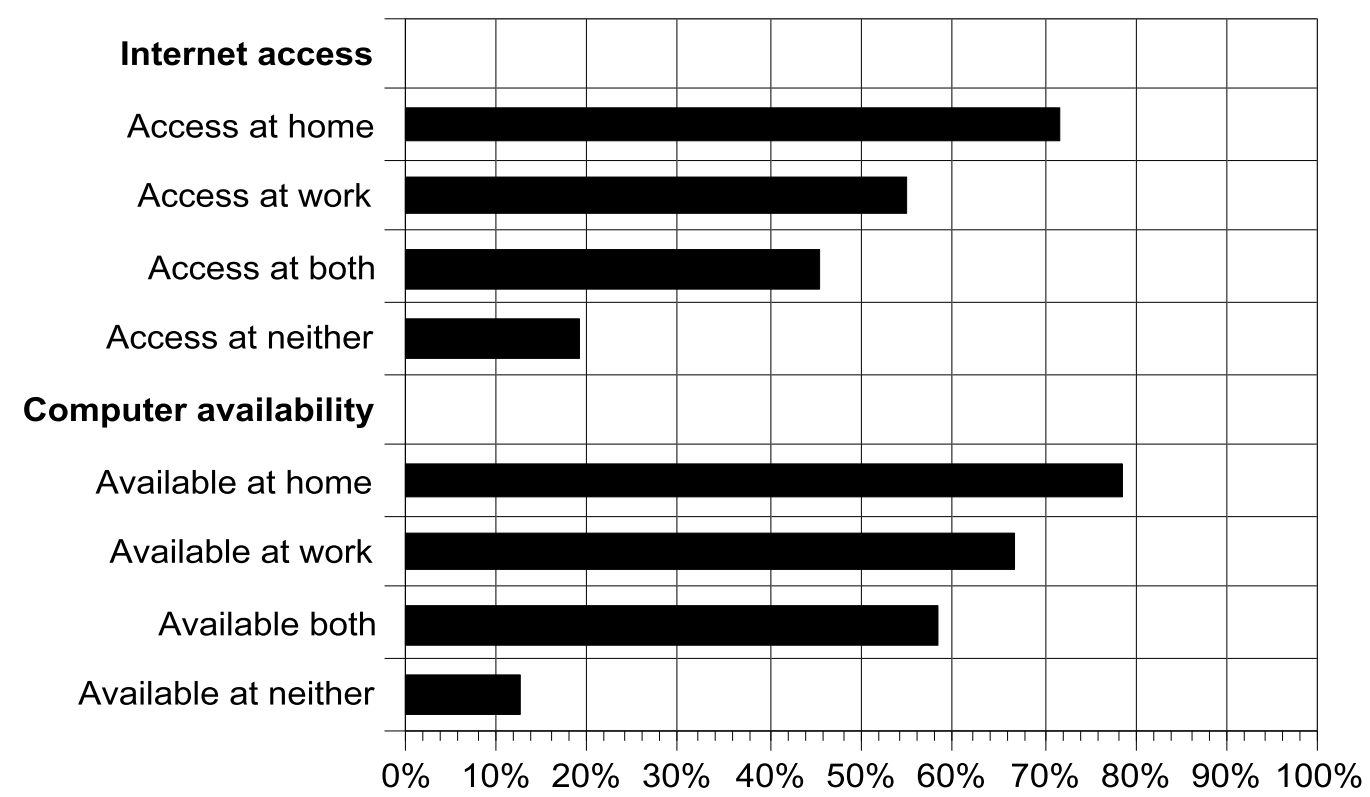

Figure 1: Computer availability and Internet access

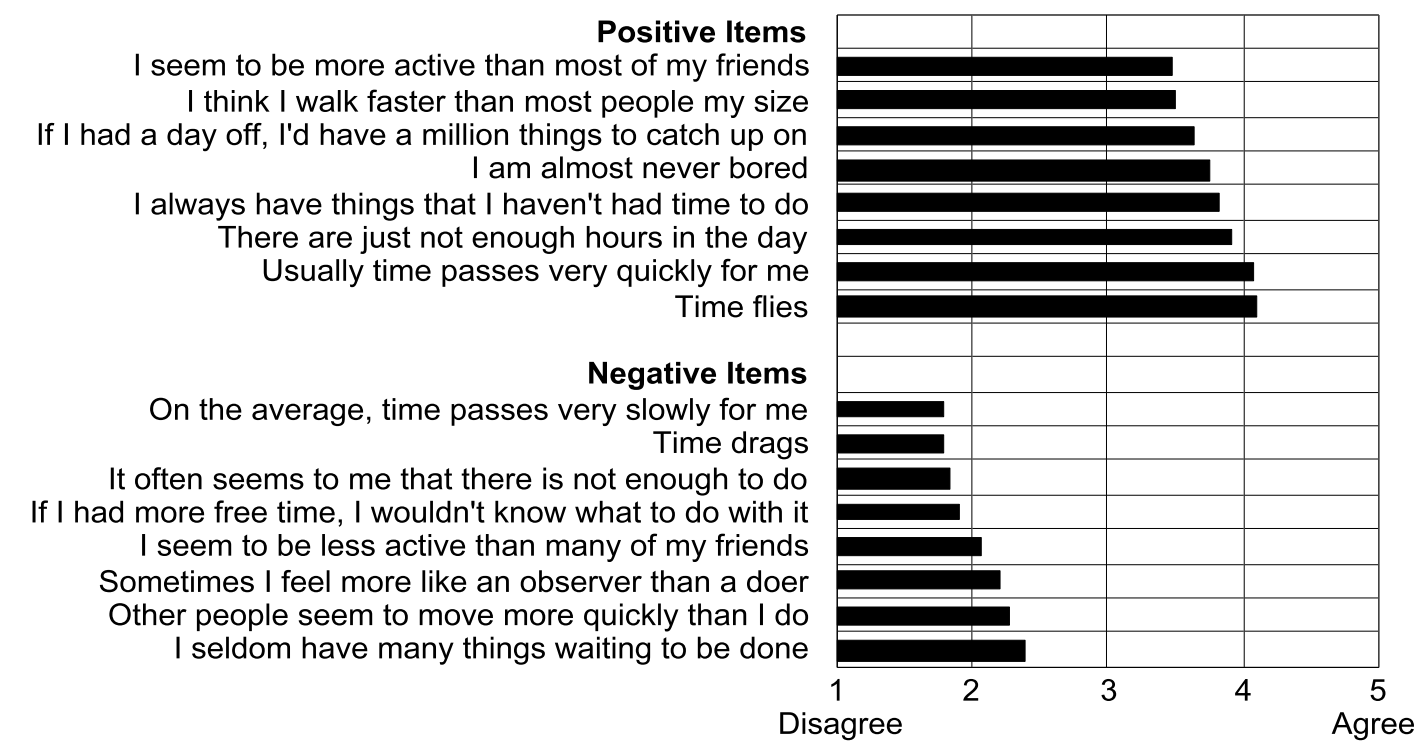

Figure 2: Activity scale items

\section{Perceptions of time-saving purchasing}

The percentage distributions of response for the seven items measuring perceptions of time-saving purchase practices are shown in Figure 3, together with the mean rating for each item. The items are listed from the one seen as the most time saving to that viewed as the least so.

Shopping and/or buying from a catalogue was seen as the most time saving of the group, followed closely by shopping on the Internet or Web. 


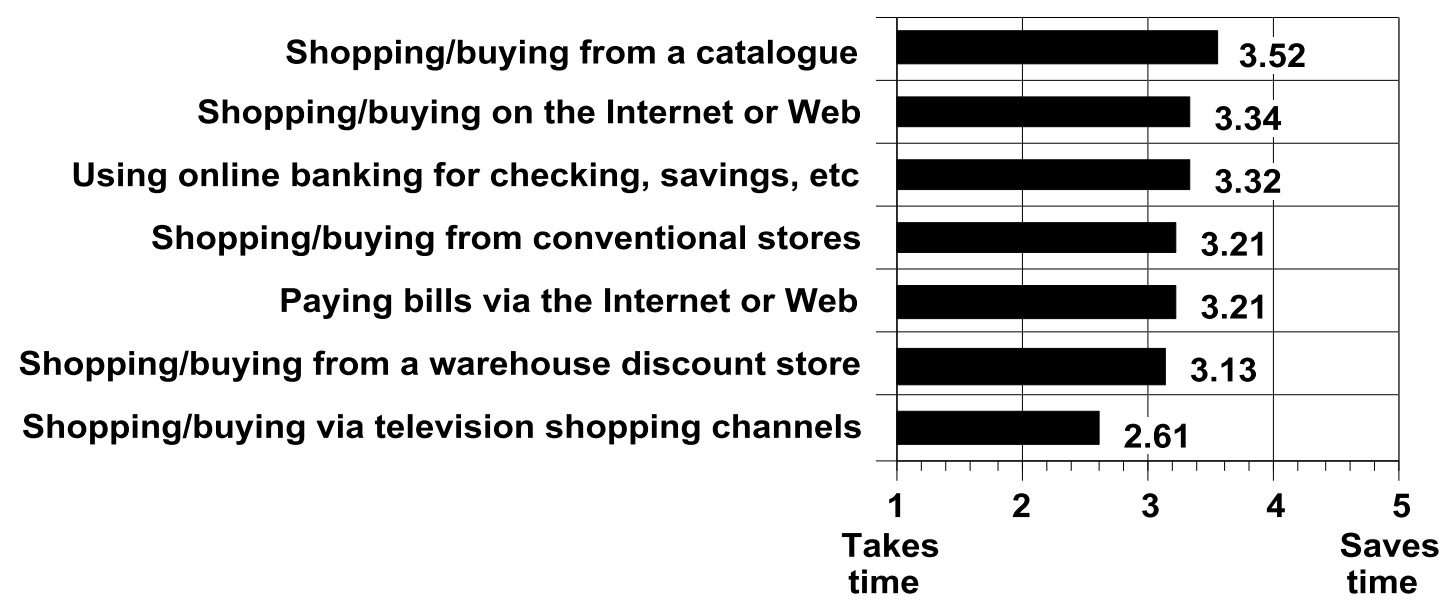

Figure 3: Ratings of time-saving practices

Another direct mode, shopping and/or buying via television shopping channels, was seen as the most time consuming. Conventional store shopping had an intermediate position, falling directly between online banking and online bill paying.

\section{Time-saving shopping practices}

The ratings of the use of 14 shopping policies in order to save time are shown in Figure 4. The items are listed from those most often to least often used. The internal consistency reliability of the 14 items was relatively high, with a coefficient alpha of .68. Shopping at the closest store and when the stores were not busy were the time-saving ploys most often used. 'Hiring out' laundry, house cleaning and lawn care were the least common practices. Buying from catalogues and from the Internet or Web ranked ninth and tenth, respectively. Thus, they were among the least common methods by which consumers 'buy time'.

\section{Activity and time saving}

The correlations between activity scores and time-saving practices are shown in
Table 2. While half the time-saving practices had a statistically significant correlation with activity scores, all the coefficients were extremely small. Given the minuscule amount of shared variance, none of the relationships can be regarded as relevant. Thus, it would not be appropriate to compare the relationships between Internet and catalogue shopping with activity level to those of other time-saving practices.

\section{Internet activity and time-saving practices}

Table 3 contains the breakdown of mean ratings of time-saving purchase practices by hours per week spent on the Internet. The latter variable is expressed in the form of categories, each containing from 16 per cent to just over 23 per cent of respondents, as shown in the lower section of the table. The analyses of variance revealed that use of the Internet and catalogue shopping ratings are all significantly related to hours per week spent on the Internet. Warehouse, television and store shopping ratings were not significantly related to online hours. 
The hurried consumer: Time-saving perceptions of Internet and catalogue shopping

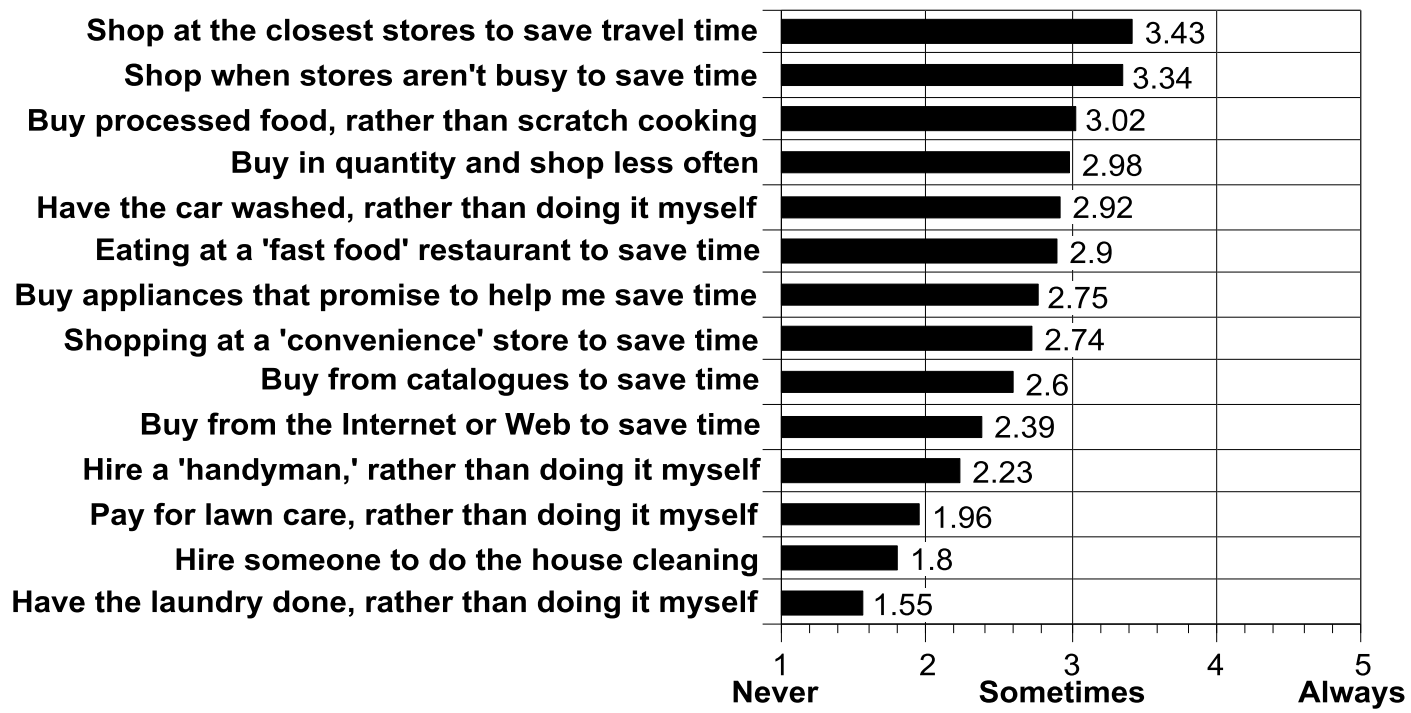

Figure 4: Time-saving shopping practices

Table 2: Correlations between time-saving practices and activity scores

\begin{tabular}{llll}
\hline & $\mathbf{r}$ & $\mathbf{P}$ & $\mathbf{N}$ \\
\hline Positively correlated items & & & \\
Have the car washed, rather than doing it myself & +0.073 & 0.003 & 1,392 \\
Buy from catalogues to save time & +0.066 & 0.007 & 1,401 \\
Buy in quantity and shop less often & +0.062 & 0.010 & 1,418 \\
Shop when stores aren't busy to save time & +0.052 & 0.026 & 1,411 \\
Buy appliances that promise to help me save time & +0.046 & 0.046 & 1,350 \\
Hire someone to do the house cleaning & +0.045 & 0.048 & 1,350 \\
Buy from the Internet or Web to save time & +0.025 & 0.181 & 1,306 \\
Pay for lawn care, rather than doing it myself & +0.017 & 0.279 & 1,246 \\
Shop at the closest stores to save travel time & +0.008 & 0.381 & 1,435 \\
Hire a handyman, rather than doing it myself & +0.002 & 0.466 & 1,324 \\
& & & \\
Negatively correlated items & & & \\
Shopping at a convenience store to save time & -0.077 & 0.002 & 1,430 \\
Have the laundry done, rather than doing it myself & -0.035 & 0.097 & 1,370 \\
Buy processed food, rather than cooking from scratch & -0.014 & 0.304 & 1,400 \\
Eating at a fast food restaurant to save time & -0.013 & 0.317 & 1,426 \\
\hline
\end{tabular}

\section{Time saving and hours worked outside the home}

The breakdown of time-saving shopping practice ratings by hours worked outside the home is shown in Table 4. Only those respondents with access to the Internet, at home, at work or both, were included in the analyses. When submitted to analyses of variance, eight of the 14 items were significantly related to hours worked at the .05 level of probability.
Buying from the Internet proved to have the second strongest relationship to hours worked outside the home. Those who did not work outside the home had the lowest mean rating for 'Buying from the Internet or Web to save time', while those who worked over 40 hours a week outside the home had the highest mean rating on this item. 'Buying from a catalogue to save time' was not significantly related to hours worked. 


\section{Alreck and Settle}

Table 3: Breakdown of ratings of time-saving perceptions by hours per week on the Internet

\begin{tabular}{|c|c|c|c|c|c|c|c|c|}
\hline \multirow[b]{2}{*}{ Hours/Week on the Internet $=$} & \multicolumn{6}{|c|}{ Mean time-saving ratings } & \multirow[b]{2}{*}{$\mathbf{F}$} & \multirow[b]{2}{*}{$\mathbf{P}$} \\
\hline & None & $<10$ & 10-19 & 20-30 & $>\mathbf{3 0}$ & All & & \\
\hline $\begin{array}{l}\text { Using online banking for checking, } \\
\text { savings, etc }\end{array}$ & 3.10 & 3.17 & 3.48 & 3.62 & 3.76 & 3.44 & 11.73 & 0.000 \\
\hline $\begin{array}{l}\text { Shopping/buying on the Internet or } \\
\text { Web }\end{array}$ & 3.10 & 3.25 & 3.53 & 3.68 & 3.79 & 3.49 & 11.60 & $\begin{array}{l}0.000 \\
0.000\end{array}$ \\
\hline Paying bills via the Internet or Web & 2.96 & 3.14 & 3.38 & 3.43 & 3.58 & 3.32 & 7.58 & 0.005 \\
\hline Shopping/buying from a catalogue & 3.35 & 3.51 & 3.56 & 3.70 & 3.78 & 3.60 & 3.78 & \\
\hline $\begin{array}{l}\text { Shopping/buying from a warehouse } \\
\text { discount store }\end{array}$ & 3.13 & 3.20 & 3.19 & 3.04 & 2.97 & 3.11 & 2.02 & 0.090 \\
\hline $\begin{array}{l}\text { Shopping/buying via television } \\
\text { shopping channels }\end{array}$ & 2.78 & 2.61 & 2.60 & 2.58 & 2.68 & 2.63 & 0.77 & 0.548 \\
\hline $\begin{array}{l}\text { Shopping/buying from conventional } \\
\text { stores }\end{array}$ & 3.22 & 3.21 & 3.13 & 3.10 & 3.14 & 3.15 & 0.62 & 0.649 \\
\hline Number $=$ & 409 & 417 & 357 & 324 & 287 & 1,794 & & \\
\hline Percent $=$ & $22.8 \%$ & $23.2 \%$ & $19.9 \%$ & $18.1 \%$ & $16.0 \%$ & $100.0 \%$ & & \\
\hline
\end{tabular}

Scale: $1=$ takes extra time, $5=$ saves time

Table 4: Breakdown of time-saving shopping practices by hours worked outside the home

\begin{tabular}{|c|c|c|c|c|c|c|c|}
\hline \multirow[b]{2}{*}{ Hours Worked $=$} & \multicolumn{5}{|c|}{ Mean values of activity score } & \multirow[b]{2}{*}{$\mathbf{F}$} & \multirow[b]{2}{*}{$\mathbf{P}$} \\
\hline & None & $<\mathbf{4 0}$ & 40 & $>40$ & All & & \\
\hline $\begin{array}{l}\text { Pay for lawn care, rather than } \\
\text { doing it myself }\end{array}$ & 2.35 & 2.03 & 1.72 & 1.89 & 1.96 & 8.35 & 0.000 \\
\hline $\begin{array}{l}\text { Buy from the Internet or Web to } \\
\text { save time }\end{array}$ & 1.71 & 2.09 & 2.06 & 2.15 & 2.04 & 6.69 & 0.000 \\
\hline $\begin{array}{l}\text { Hire someone to do the house } \\
\text { cleaning }\end{array}$ & 1.92 & 1.57 & 1.63 & 1.91 & 1.75 & 6.45 & 0.000 \\
\hline $\begin{array}{l}\text { Have the laundry done, rather than } \\
\text { doing it myself }\end{array}$ & 1.59 & 1.43 & 1.34 & 1.66 & 1.51 & 6.23 & 0.000 \\
\hline $\begin{array}{l}\text { Hire a handyman, rather than doing } \\
\text { it myself }\end{array}$ & 2.37 & 2.28 & 2.00 & 2.13 & 2.18 & 4.20 & 0.006 \\
\hline $\begin{array}{l}\text { Eating at a fast food restaurant to } \\
\text { save time }\end{array}$ & 2.61 & 2.82 & 2.87 & 2.88 & 2.81 & 3.92 & 0.008 \\
\hline $\begin{array}{l}\text { Buy processed food, not cook from } \\
\text { scratch }\end{array}$ & 2.77 & 3.04 & 2.87 & 2.94 & 2.92 & 3.10 & 0.026 \\
\hline $\begin{array}{l}\text { Shopping at a convenience store to } \\
\text { save time }\end{array}$ & 2.56 & 2.81 & 2.73 & 2.74 & 2.72 & 2.92 & 0.033 \\
\hline Buy from catalogues to save time & 2.48 & 2.42 & 2.61 & 2.54 & 2.51 & 1.75 & 0.154 \\
\hline $\begin{array}{l}\text { Shop at the closest stores to save } \\
\text { travel time }\end{array}$ & 3.31 & 3.44 & 3.49 & 3.47 & 3.44 & 1.68 & 0.170 \\
\hline $\begin{array}{l}\text { Buy appliances that promise to } \\
\text { help me save time }\end{array}$ & 2.83 & 2.84 & 2.68 & 2.70 & 2.75 & 1.58 & 0.193 \\
\hline Buy in quantity and shop less often & 3.03 & 2.92 & 3.00 & 2.99 & 2.98 & 0.59 & 0.622 \\
\hline $\begin{array}{l}\text { Have the car washed, rather than } \\
\text { doing it myself }\end{array}$ & 2.99 & 2.89 & 2.84 & 2.93 & 2.91 & 0.55 & 0.648 \\
\hline $\begin{array}{l}\text { Shop when stores aren't busy to } \\
\text { save time }\end{array}$ & 3.34 & 3.38 & 3.40 & 3.32 & 3.36 & 0.50 & 0.684 \\
\hline Number $=$ & 258 & 345 & 335 & 414 & 1,352 & & \\
\hline Percent $=$ & $19.1 \%$ & $25.5 \%$ & $24.8 \%$ & $30.6 \%$ & $100.0 \%$ & & \\
\hline
\end{tabular}

Activity scale scores: $1=$ never, $5=$ always 
The hurried consumer: Time-saving perceptions of Internet and catalogue shopping

Table 5: Cross-tabulation of activity level by hours working outside the home

\begin{tabular}{lccccc}
\hline \multicolumn{7}{c}{ Hours working outside the home } \\
nctivity level & None \% & Under $\mathbf{4 0 \%}$ & $\mathbf{4 0 ~ H o u r s \%}$ & Over $\mathbf{4 0 \%}$ & Total \% \\
\hline Low & 9.1 & 9.6 & 8.1 & 7.2 & 34.1 \\
Medium & 5.5 & 8.8 & 8.0 & 9.6 & 31.8 \\
High & 3.6 & 7.7 & 9.3 & 13.4 & 34.1 \\
Total & 18.2 & 26.1 & 25.4 & 30.3 & 100.0 \\
\hline
\end{tabular}

Chi-Square $=84.2$, d.f. $=6$, Prob. $=0.000$

\section{Activity level and hours worked outside the home}

Respondents were classified into three, approximately equal-sized groups according to whether their activity scale scores were low, medium or high. The cross-tabulation of activity levels with hours worked outside the home is shown in Table 5. As might be expected, hours worked outside the home were directly and significantly related to activity level and perceived time pressure.

\section{CONCLUSION}

\section{Summary}

The results of the survey can be summarised as follows:

- the demographic distributions of the sample were balanced by age and sex and were somewhat more upscale than the underlying population (Table 1)

- a very high proportion of the sample had computer availability and Internet access at home, at work or both (Figure 1)

- activity levels revealed by the activity scale of the F-A-S-T Time Orientation Test were only slightly higher than those of the standardisation sample (Figure 2)

- shopping by catalogue and on the Internet were viewed as more 'time saving' than other, traditional modes of shopping and buying (Figure 3)
- catalogue and Internet shopping ranked ninth and tenth among the 14 time-saving shopping practices listed (Figure 4)

- activity scores were significantly related to catalogue buying to save time, but not to Internet buying to save time (Table 2)

- time spent per week on the Internet was positively and significantly related to Internet banking, shopping and bill paying and to catalogue buying (Table 3)

- hours worked outside the home were significantly related to Internet buying to save time, but not to catalogue buying (Table 4)

- hours worked outside the home were also significantly related to activity level as measured by the activity scale (Table 5).

\section{Research questions}

This study was designed to explore the consumers' perceptions of shopping and buying time saving or consumption, their use of time-saving practices when buying and the effect of activity level on these perceptions and practices. The response to the first question (Do consumers perceive Internet and catalogue shopping and/or buying as more time saving or time consuming than other modes of shopping and/or buying?) was that both Internet and catalogue shopping were viewed very favourably regarding time saving when compared to other shopping 
and buying modes. Television shopping channels were seen as most time consuming.

The second research question was 'How often do consumers use Internet and catalogue shopping as time-saving methods of shopping, compared to other time-saving practices?' Respondents reported that they used catalogue and Internet shopping to save time very infrequently compared to other practices (eg shopping at the closest store or during slow times). Thus, there was a sharp contrast between their perceptions and their practices.

The third question was 'To what degree do consumer activity levels affect their time-saving perceptions and use of time-saving shopping methods?' The survey shows that self-reported activity levels had little effect on time-saving perceptions or practices. Hours worked outside the home and hours spent per week on the Internet were significantly related to perceptions and practices.

\section{Interpretations}

The image of Internet and catalogue shopping is clearly quite positive with regard to their ability to save the consumer time, yet respondents reported only rarely using these purchase methods to save time. What, then, might be the reason for this inconsistency? The apparent conflict between time-saving perceptions and practices might require further research to clarify. One explanation may be that, as noted earlier, 'convenience' implies economy of both time and effort. Thus, consumers might perceive online and catalogue shopping as a means to save time, but regard them as requiring too much effort to employ routinely. The role of perceived effort might be seen as especially important to adoption or rejection of online shopping and buying.

\section{Implications}

Although admittedly somewhat speculative, these interpretations have some strong implications for database marketing, especially via the Internet. The degree to which both the relatively inexperienced and the highly experienced Internet users find the World Wide Web to be not only quick, but easy to use will certainly have a strong effect on their choice of outlets and their shopping and buying practices. Conversely, if they find online purchasing difficult or time consuming, they will be discouraged from future Internet shopping.

One survey found that in 2000 over a quarter of online purchase attempts failed when would-be buyers left the site or abandoned their shopping carts before completing the transaction. ${ }^{28}$ Such findings support the conclusion that the effort required to overcome difficulty online is a major inhibiting factor. Nor would one expect that such frustrated buyers would quickly return to a mode of shopping that had failed them. To alleviate this problem, the author of the study suggests, among other options, the application of relationship management strategies.

Certainly the 'one size fits all' approach to website creation will not enhance the facility and speed of online shopping. Tailoring websites to the individual conditions, needs and preferences of each visitor based on an enhanced database would reduce both the time and the effort required of the buyer. And to the degree buyers are successful and happy, so, too, are those who market to them.

\section{References}

1 Ben Zur, H. and Breznitz, S. J. (1981) 'The effect of time pressure on risky choice behavior', Acta Psychologica, Vol. 47, February, pp. 89-104.

2 Edland, A. (1987) 'Change of preferences under time pressure: Choices and judgments',

Scandinavian Journal of Psychology, Vol. 28, No. 4, pp. 322-330. 
3 Edland, A. and Slovic, P. (1990) 'Choices and judgments of incompletely described decision alternatives under time pressure', Acta Psychologica, Vol. 75, November, pp. 153-169.

4 Tversky, A. and Shafir, E. (1992) 'Choice under conflict: The dynamics of deferred decision', Psychological Science, Vol. 3, November, pp. 358-361.

5 Stiensmeier-Pelster, J. and Schurmann, M. (1993) 'Information processing in decision making under time pressure: The influence of action versus state orientation', in Svenson, O. and Maule, A. J. (eds) 'Time pressure and stress in human judgment and decision making', Plenum Press, New York, pp. 241-253.

6 Svenson, O. and Benson, L. III (1993) 'Framing and time pressure in decision making', in Svenson, O. and Maule, A. J. (eds) 'Time pressure and stress in human judgment and decision making', Plenum Press, New York, pp. 133-144.

7 Verplanken, B. (1993) 'Need for cognition and external information search: Responses to time pressure during decision-making', Journal of Research in Personality, Vol. 27, September, pp. 238-252.

8 Edland, A. (1994) 'Time pressure and the application of decision rules: Choices and judgments among multiattribute alternatives', Scandinavian Journal of Psychology, Vol. 35, September, pp. 281-291.

9 Dhar, R. and Nowlis, S. M. (1999) 'The effect of time pressure on consumer choice deferral', Journal of Consumer Research, Vol. 25, No. 4, pp. 369-384.

10 Wright, P. (1974) 'The harassed decision maker: Time pressures, distractions, and the use of evidence', Journal of Applied Psychology, Vol. 59, October, pp. 555-561.

11 Nowlis, S. M. (1995) 'The effect of time pressure on the choice of brands that differ in quality, price, and product features', Marketing Letters, Vol. 6, October, pp. 287-296.

12 Cristol, S. M. and Sealey, P. (1996) 'Replacement marketing', Marketing Management, Vol. 5, Spring, pp. 12-22.

13 Bhatnagar, A., Misra, S. and Rao, H. R. (2000) 'On risk, convenience, and Internet shopping behavior', Communications of the Association for Computing Machinery, Vol. 43, No. 11, pp. 98-105.
14 Eastlick, M. A. and Feinberg, R. A. (1999) 'Shopping motives for mail catalog shopping', Journal of Business Research, Vol. 45, No. 3, pp. 281-290.

15 Bellman, S., Lohse, G. L. and Johnson, E. J. (1999) 'Predictors of online buying behavior', Communications of the Association for Computing Machinery, Vol. 42, No. 12, pp. 32-38.

16 Donthu, N. and Garcia, A. (1999) 'The Internet shopper', Journal of Advertising Research, Vol. 39, No. 3, pp. 52-58.

17 Ibid.

18 Citrin, A. V., Sprott, D. E., Silverman, S. N. and Stem, D. E. Jr. (2000) 'Adoption of Internet shopping: The role of consumer innovativeness', Industrial Management + Data Systems, Wembley, Vol. 100, No. 7, pp. 294-300.

19 Shim, S., Eastlick, M. A., Lotz, S. L. and Warrington, P. (2001) 'An online prepurchase intentions model: The role of intention to search', Journal of Retailing, Vol. 77, No. 3, pp. 397-416.

20 Szymanski, D. M. and Hise, R. T. (2000) 'E-satisfaction: An initial examination', Journal of Retailing, Vol. 76, No. 3, pp. 309-322.

21 Wolfinbarger, M. and Gilly, M. C. (2001) 'Shopping online for freedom, control, and fun', California Management Review, Vol. 43, No. 2, pp. 34-55.

22 Degeratu, A. M., Rangaswamy, A. and Wu, J. (2000) 'Consumer choice behavior in online and traditional supermarkets: The effects of brand name, price, and other search attributes', International Journal of Research in Marketing, Amsterdam, Vol. 17, No. 1, pp. 55-78.

23 Donthu and Garcia (1999) op. cit.

24 Balabanis, G. and Reynolds, N. L. (2001) 'Consumer attitudes towards multi-channel retailers' web sites: The role of involvement, brand attitude, Internet knowledge and visit duration', Journal of Business Strategies, Vol. 18, No. 2, pp. 105-132.

25 Bhatnagar et al. (2000) op. cit.

26 Alreck, P. L. and Settle, R. B. (1991) 'F-A-S-T: A Standardized Measure of Time Traits', Proceedings of the Special Conference on Time and Consumer Behavior.

27 Ibid.

28 Bayan, R. (2000) 'How business owners can prevent online shopping failures link-up', Medford, Vol. 17, No. 4, pp. 32-33. 
